\title{
Correction to: The Endocranial Cast of Indohyus (Artiodactyla, Raoellidae): The Origin of the Cetacean Brain
}

\author{
Maeva J. Orliac ${ }^{1}$ (D. J. G. M. Thewissen ${ }^{2}$
}

Published online: 26 May 2021

๑) Springer Science+Business Media, LLC, part of Springer Nature 2021

Correction to: Journal of Mammalian Evolution https://doi.org/10.1007/s10914-021-09552-x

The original version of this article was unfortunately published online without the final approval from the author and the Editor-in-Chief, and errors were introduced at some stage during the production process.

The original article has been corrected.

The original article can be found online at https://doi.org/10.1007/ s10914-021-09552-x.

Maeva J. Orliac

maeva.orliac@umontpellier.fr

1 Institut Des Sciences de L'Evolution de Montpellier,

Universite de Montpellier, CNRS, EPHE, IRD, Place Eugene

Bataillon, 34095, Cedex 5 Montpellier, France

2 Department of Anatomy and Neurobiology, Northeast Ohio Medical University, 4209 State Route 44, Rootstown, OH 44272, USA 